\section{Interventions for skin changes caused by nerve damage in leprosy}

\author{
Liv Merete Reinar, Louise Forsetlund, Arild Bjørndal, \\ Diana Lockwood
}

The independent commentary was written by Maria Angela Bianconcini Trindade

\section{ABSTRACT}

BACKGROUND: More than three million persons are disabled by leprosy worldwide. The main complication of sensory nerve damage is neuropathic ulceration, particularly of the feet. In this review we explored interventions that can prevent and treat secondary damage to skin and limbs.

OBJECTIVE: To assess the effects of self-care, dressings and footwear in preventing and healing secondary damage to the skin in persons affected by leprosy.

\section{METHODS:}

Search methods: We searched the Cochrane Skin Group Specialised Register (April 2008), the Cochrane Central Register of Controlled Trials (The Cochrane Library Issue 1, 2008), MEDLINE (from 2003 to April 2008), EMBASE (from 2005 to April 2008), CINAHL (1982-2006) and LILACS (1982- April 2008) as well as online registers of ongoing trials (April 2008).

Selection criteria: Randomised controlled trials involving anyone with leprosy and damage to peripheral nerves treated with any measures designed to prevent damage with the aim of healing existing ulcers and preventing development of new ulcers.

Data collection and analysis: Two authors assessed trial quality and extracted data.

MAIN RESULTS: Eight trials with a total of 557 participants were included. The quality of the trials was generally poor. The interventions and outcome measures were diverse. Although three studies that compared zinc tape to more traditional dressings found some benefit, none of these showed a statistically significant effect. One trial indicated that topical ketanserin had a better effect on wound healing than clioquinol cream or zinc paste, RR was 6.00 ( $95 \%$ Cl 1.45 to 24.75). We did not combine the results of the two studies that compared topical phenytoin to saline dressing, but both studies found statistically significant effects in favour of phenytoin for healing of ulcer (SMD $-2.34 ; 95 \% \mathrm{Cl}-3.30$ to -1.39 ; and SMD $-0.79 ; 95 \% \mathrm{Cl}-1.20$ to 0.39 ). Canvas shoes were not much better than PVC-boots, and double rocker shoes did not promote healing much more than below-knee plasters.

AUTHORS' CONCLUSIONS: One study suggested that topical ketanserin is more effective than clioquinol cream or zinc paste. Topical phenytoin (two studies) may be more effective than saline dressing regarding ulcer healing. For the other dressings the results were equivocal. Canvas shoes were a little better than PVC-boots, but not significantly, and the effect of double rocker shoes compared to below-knee plasters was no different in promoting the healing of ulcers. No side effects were documented.

This is the abstract of a Cochrane Review published in the Cochrane Database of Systematic Reviews (CDSR) 2013, ISSUE 1, ART. NO. CD004833. DOI: 10.1002/14651858.CD004833.pub3 (http://onlinelibrary.wiley.com/doi/10.1002/14651858.CD004833.pub3/abstract). For full citation and authors details, see reference 1
The full text is freely available, for Latin America and the Caribbean, from: http://cochrane.bvsalud.org/cochrane/main.php?lib=COC\&se archExp=Interventions\%20and\%20for\%20and\%20skin\%20and\%20 changes\%20and\%20caused\%20and\%20by\%20and\%20nerve $\% 20$ and\%20damage\%20and\%20in\%20and\%20leprosy\&lang=pt (this link may be temporary)

\section{REFERENCE}

1. Reinar LM, Forsetlund L, Bjørndal A, Lockwood D. Interventions for skin changes caused by nerve damage in leprosy. Cochrane Database of Syst Rev. 2008;(3):CD004833.

\section{COMMENTS}

This systematic review evaluated the effects of self-care, dressings and footwear for preventing and healing secondary damage to the skin among individuals affected by leprosy. The search was conducted only using online registers of ongoing trials up to 2008 , a time when many studies clearly lacked reporting of methods, which was suggested in this review by the generally poor quality of the trials and the differences in interventions and measurements of results. Nonetheless, the results from this review showed that three studies using zinc tape had better but non-significant results, compared with other more traditional dressings; and that ketanserin was better than clioquinol or zinc paste, with a significant effect, and likewise, phenytoin was better than saline dressings. On the other hand, no studies showed any significant effects from PVC canvas shoes in relation to plaster-cast rocker boots up to below the knee.

This review highlights the need for further trials on the efficacy of interventions for skin abnormalities caused by nerve damage caused by leprosy, with comparisons between different types of dressings and/ or between dressings and topical agents, between different types of footwear and between self-care and educational programs. This is important because more than three million people are disabled by leprosy worldwide and, considering that the main complication from sensory nerve damage is neuropathic ulceration, particularly of the feet, treatment can improvement these individuals' quality of life at low cost.

Maria Angela Bianconcini Trindade, MD, PhD. Dermatologist and leprologist; Scientific Researcher V, Medical Investigation Laboratory for Immunodermatopathology, Division of Clinical Dermatology, Hospital das Clínicas, Faculdade de Medicina da Universidade de São Paulo (HC-FMUSP), and Professor of Postgraduate Studies, Health Institute, Health Department of the State of São Paulo, Brazil. 